\title{
Observations of wind and waves in the central Bay of Bengal during BOBMEX-99 and their effect on mixed layer depth variability due to forced mixing
}

\author{
J Swain, R K Shukla, A Raghunadha Rao, J K Panigrahi and N R Venkitachalam \\ Naval Physical and Oceanographic Laboratory, Thrikakkara, Kochi 682 021, India
}

Time-series wind and wave measurements were carried out onboard INS Sagardhwani in the central Bay of Bengal during BOBMEX-99. Various other marine meteorological and oceanographic measurements relevant to monsoon studies were also collected simultaneously. The observed variations of wind and waves and the associated mixed layer depth (MLD) variability based on both temperature and density criteria at 3 hourly intervals are presented in this paper as a case study. At the time-series location $\left(13^{\circ} \mathrm{N}, 87^{\circ} \mathrm{E}\right)$ wind varied between 6 and $16 \mathrm{~m} / \mathrm{s}$ and the predominant direction was southwesterly. The significant wave height and period varied from 1.9 to $3.7 \mathrm{~m}$ and 8 to $13 \mathrm{~s}$ respectively. Some of the available statistical predictive methods for the determination of MLD by forced mixing are utilized to test the extent of mechanical mixing within the top layer of water by the local wind and wave activity. The same is extended to formulate a new empirical relation for gross estimation of effective depth within which the sound energy is generally trapped during its transmission in the surface duct. The present analysis aiming for estimation of observed MLD variability (35 to $75 \mathrm{~m}$ ) using the suggested simple empirical relation reveals that, the mixed layer variability observed during the experiment depends on both local ocean variability as well as remote forcing as reported earlier.

\section{Introduction}

The Bay of Bengal Monsoon Experiment (BOBMEX-99) was planned and executed as a part of the ongoing national program called Indian Climate Research Programme (ICRP). The experiment lasted for about 45 days and various oceanographic and marine meteorological parameters including wind and waves were collected onboard two research ships which occupied two predetermined positions in the Bay of Bengal. The primary concern of this field experiment was to study the air-sea coupling and intraseasonal variability over the Bay during the summer monsoon. The NPOL ship INS Sagardhwani (INSS) carried out her BOBMEX-99 mission in four different phases between 15th July and 30th August 1999. She operated from Chennai port and occu- pied the time-series station in the central Bay of Bengal $\left(13^{\circ} \mathrm{N}, 87^{\circ} \mathrm{E}\right.$, figure 1) for a period of five to six days in each phase. In addition to the timeseries measurements onboard INSS, the ship also carried out spatial observations between off Chennai and the time-series station at every 30 mile intervals. The observed wind and wave variability based on these measurements was discussed in our earlier study (Swain et al 2000). It is well understood that the sea-state or the waves in the ocean play a dominant role in the air-sea interaction process of the coupled ocean-atmosphere system. Meteorologists have also recognised sea-state prediction as part of the weather. The present paper discusses one of the important oceanographic variabilities such as the role of wind and waves in mixing the upper few meters of the sea water which is termed as forced mixing and sug-

Keywords. Wind, waves and MLD; forced mixing; MLD variability; prediction of MLD; BOBMEX-99. 


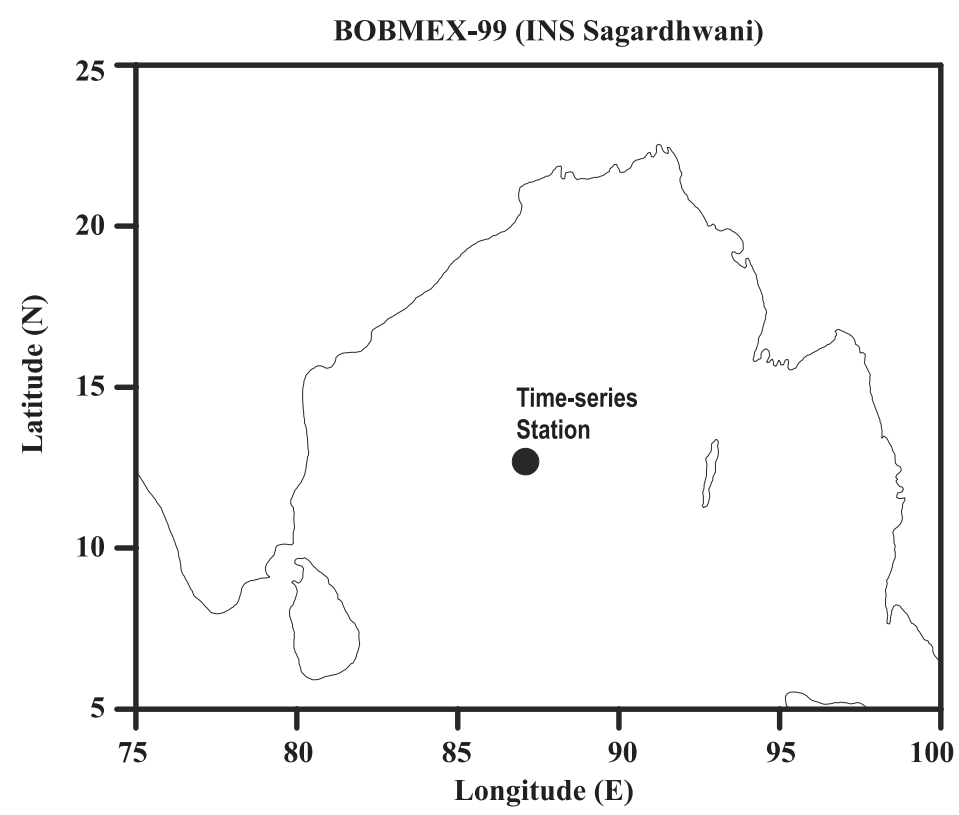

Figure 1. Time-series location in the central Bay of Bengal.

gests a predictive empirical relation to estimate MLD.

The term 'forced mixing' is commonly understood as mechanical mixing primarily due to the waves and currents. Some attempts were made in the past to determine the depth of mixing directly from observed winds (Rossby and Montgomery 1935; Lumby 1955; Kitaigorodskii 1960). Although wind is the direct cause of mixing, the actual mixing of water at the top layers is accomplished through secondary effects such as windinduced surface gravity waves and currents. The waves of different heights and periods and the turbulence caused by the breaking of waves are the major part of the local mechanical forcing responsible for deepening of the well mixed layer. The mixed layer in this study is defined as the column of water from surface to a depth at which the temperature of water drops by $0.2^{\circ} \mathrm{C}$ from the sea surface temperature (SST) and an equivalent drop in the density (sigma-t) based on the observed profiles. The mixed layer depth (MLD) criterion has been decided on to characterise the surface duct (sonic layer depth) in which the sound energy is generally trapped during its transmission. This phenomenon has direct relevance for the sonar range prediction or detection of underwater targets and various other applications. This study does not include the direct contribution of wind-induced surface currents for the determination of MLD, although its contribution towards mechanical mixing cannot be disregarded. However, the effect of prevailing wind and waves may largely take care of forced mixing in the statistical/empirical formulation which will be discussed later in this paper, although the physical basis for relating MLD to wind and waves alone can not be well justified.

\section{Data and methods}

The three hourly time-series wind data onboard INSS were collected at 10 meters from the sea surface using the ship's anemometer and by installing a shelf-recording anemograph (Model No. 112, Dyna-Vane Wind Recording System, T.S.K., Japan). The measured wind speed accuracy of the anemograph is $0.5 \mathrm{~m} / \mathrm{s}$ and wind direction accuracy is about 5 degrees. Standard quality checks have been followed for TSK anemograph winds used in this analysis and compared with the ship's anemometer data. The true wind direction is estimated using the ship's heading at the timeseries station. Simultaneous, wave data were collected using the ship-borne wave recorder (SBWR, MK-III, W.S. Ocean Systems, U.K.) fitted onboard INSS. The digital wave data collected for the 20 minute period is used for computing the significant wave height $(\mathrm{Hs})$ and period $(\mathrm{Ts})$ through spectral analysis. The Mini STD (Sensordata a.s, Norway) with temperature resolution $0.005^{\circ} \mathrm{C}$ and accuracy $0.01{ }^{\circ} \mathrm{C}$ was lowered up to $500 \mathrm{~m}$ and the temperature profiles were collected every three hourly. A sample temperature and the corresponding sigma-t profiles of Mini STD is shown in figure 2 which indicates the depth of mixed layer. Following, the criterion mentioned above (drop of $0.2^{\circ} \mathrm{C}$ from SST), MLD values are estimated for the complete time-series. The equivalent MLD estimates based on the observed sigma-t profiles are obtained at the depth where sigma-t exceeds by 


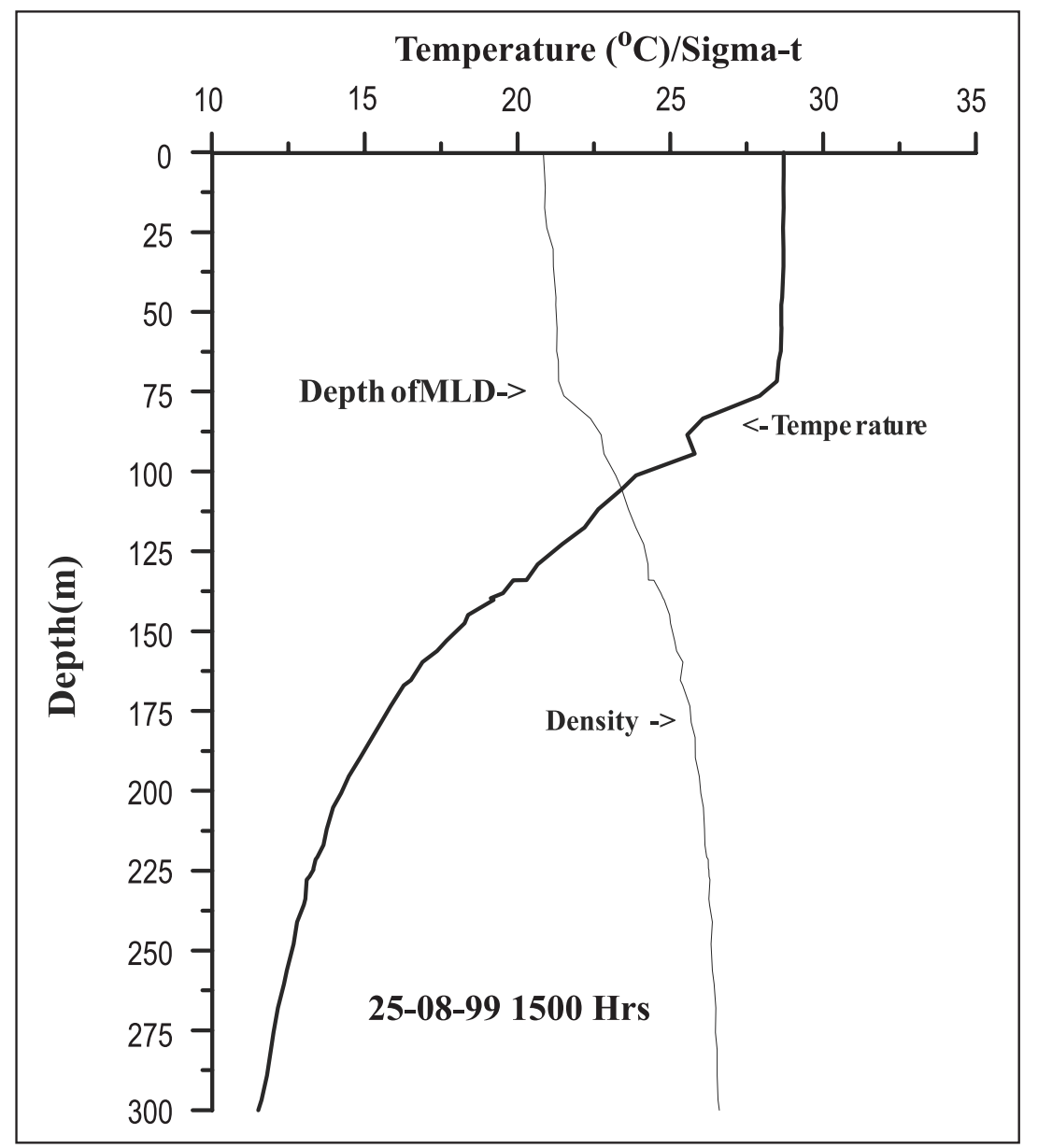

Figure 2. A sample mini STD profile showing depth of MLD.

1.0 from the surface which happened to fall within the thermocline in most cases. There is relatively a smaller variation/gradient of sigma-t within the density mixed layer defined here, i.e., around $25 \mathrm{~m}$ of water depth as shown in figure 2 , is solely due to the salinity effect and the surface duct extends further below up to the base of the next prominent density gradient considered here as density mixed layer depth. By and large, the MLD values obtained based on both these criteria are shown in figure 3 for their comparison. Excepting few data points, all the MLD values obtained based on both the above criteria more or less agree (coefficient of correlation 0.86 ) within $\pm 5 \mathrm{~m}$, probably because the time-series location is in the central Bay. The variations are considerably high in the northern Bay of Bengal (Bhat et al 2001). Since, there is a good agreement between the MLD values considering both criteria at the time-series location of INSS in the central Bay, the MLD based on the temperature criterion alone is considered for further analysis. Therefore, the discussion on MLD later in this paper is referred to temperature criterion unless a specific mention is made for density. As discussed earlier, INSS completed her mission in four phases. However, due to malfunctioning of SBWR during phase III, only the data collected during the remaining other three phases could be used in this investigation.

\section{Results and discussion}

The wind and wave climate in the Bay of Bengal (Hastenrath and Lamb 1979; Young and Holland 1996) suggests that, the observed wind and wave activity in the Bay during the rough weather season (May-September) is primarily controlled by the southwest monsoon activity over the tropical Indian Ocean. During July and August, the southwesterly winds sweep the south central Bay of Bengal and the wind speed reaches up to 9 to $15 \mathrm{~m} / \mathrm{s}$ in July which is the peak of the southwest monsoon. The mean wave height in the central Bay during July and August reaches up to 2.5 and $2.0 \mathrm{~m}$ respectively (Swain 1999). The mean monthly MLD during July and August is around 60 and $50 \mathrm{~m}$ (Hastenrath and Greischar 1989) respectively. However, the observed variability in any particular month or year may depart from the 


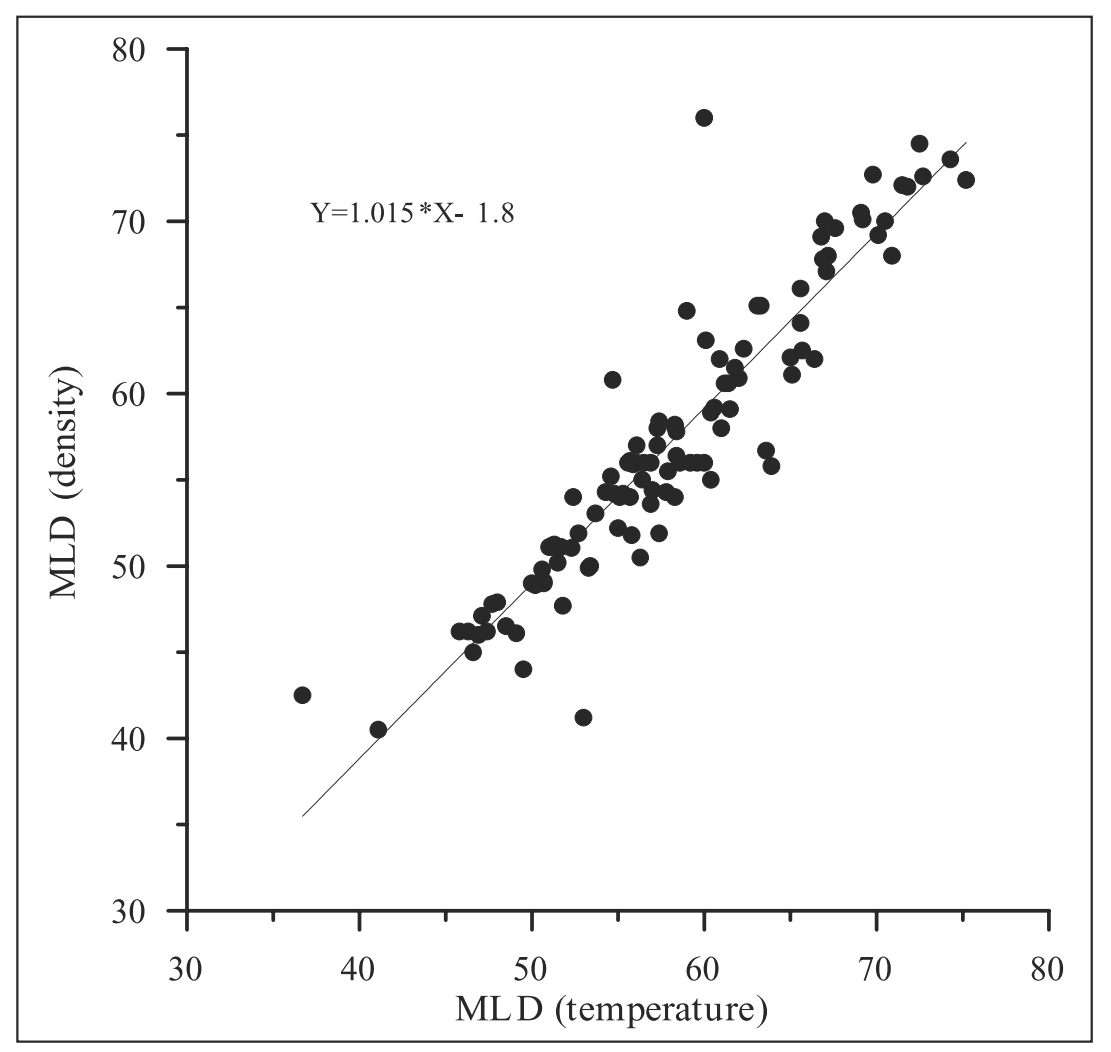

Figure 3. Comparison between the temperature and density mixed layer depth (MLD in m) at the time-series location (data from phase I, II and IV combined).

climatological figures which will be discussed in the following sections.

\subsection{Observed wind, wave and $M L D$ variability}

The observed wind speed, Hs, Ts and MLD (following temperature criterion) variations during the three different phases (I, II and IV) of BOBMEX mission are presented in figure 4. It may be seen that at the time-series station, winds varied between 6 and $16 \mathrm{~m} / \mathrm{s}$ and the direction was more or less steady around southwest $\left( \pm 30^{\circ}\right)$. Hs, Ts and MLD varied from 1.9 to $3.7 \mathrm{~m}, 8$ to $13 \mathrm{~s}$, and 35 to $75 \mathrm{~m}$ respectively. Figure 4 reveals that, wind speed, Hs and MLD have a decreasing trend during phase I and IV and interestingly an increasing trend during phase II. The observed Ts show a peak during the middle of phase I, and it decreases and increases respectively during phase II and IV respectively. In general, the observed Ts variations do not correlate with $\mathrm{Hs}$ which is a common feature in the Arabian Sea and Bay of Bengal. Ts may vary depending on the magnitude of local windwave activity and the amount of swell energy that propagates from the distant areas of wave generation. As the present data set belongs to the southwest monsoon season, the winds are gener- ally steady from southwest in the central Bay and the swell waves which propagate into the study area are also from southwest. However, the composition of sea-state namely, wind-seas and swell at the observation point depends on the variation of the wind field along the direction of wave propagation and over a larger fetch distance. Four sample wave spectra showing the composition of sea-state are shown in figure 5 . The spectra are selected during three different stages of wave growth as indicated with stars in figure 4 along the plot shown for Hs. At the beginning of phase I wind was probably strong and the wind-sea energy was higher compared to the energy of swell waves (figure 5a). As the winds dropped, the swell waves dominated in the spectrum and Hs decreased gradually. In case of phase II, the wave spectrum shown in figure 5(c) belongs to the end of measurement. It is noticed that there was a steady increase of wind speed in the past and the wave height also increased accordingly so that the wind-sea energy is predominant in the observed spectrum. The same is the case with spectrum as shown in figure $5(\mathrm{~d})$, but the wind has just withdrawn from the study area and the swell energy is very weak. These spectra indicate that, the composition of sea-state or the coupling between wind and waves strictly depend on the magnitude of local wind and the propagation of 


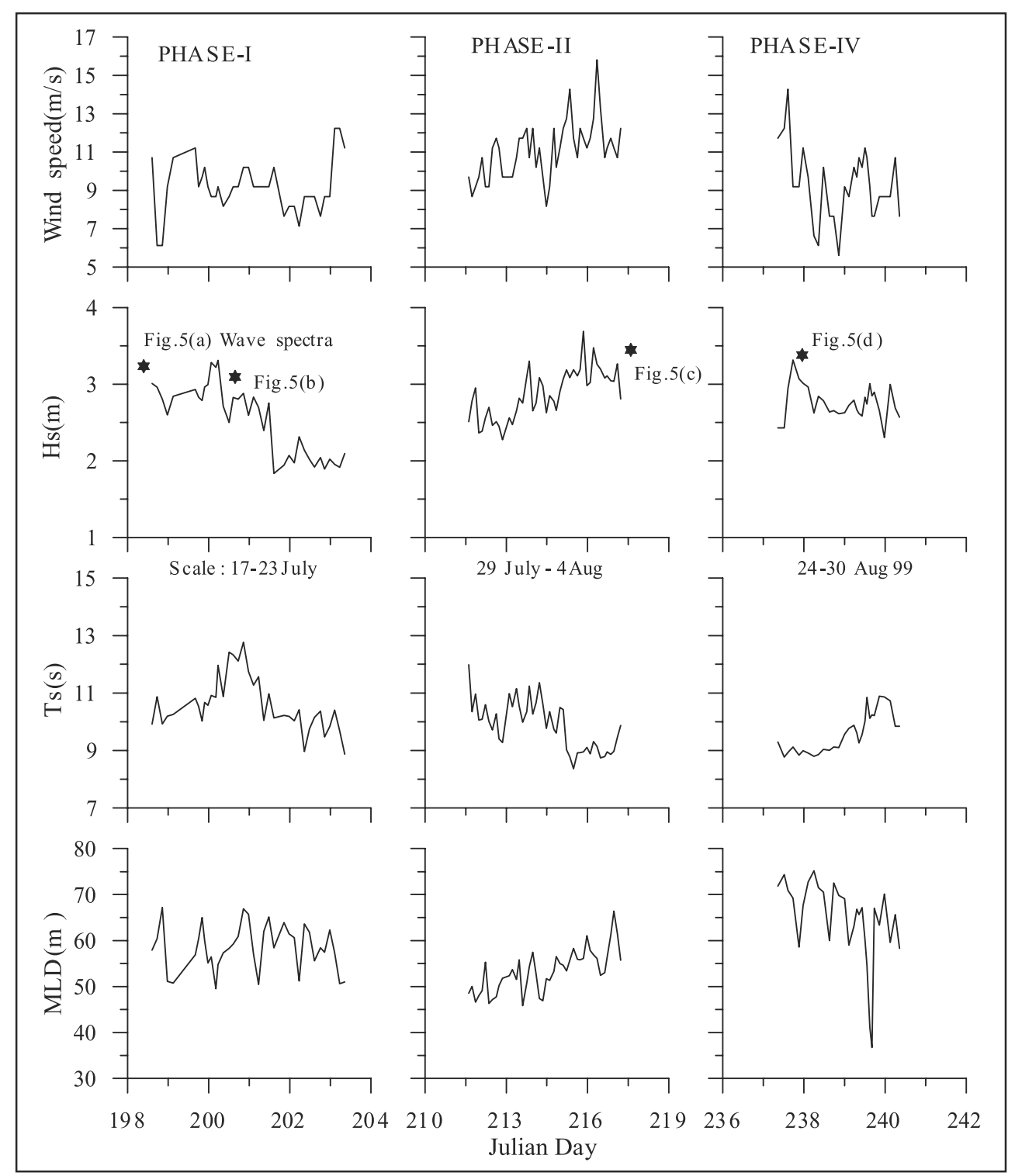

Figure 4. Variations of wind speed, significant wave height, significant wave period and mixed-layer depth in the central Bay of Bengal.

swell waves from distant generating areas. Hence, the effect of swells needs to be considered while parameterising the MLD variability due to wave forcing. In this study, the observed wind, Hs and MLD variations as shown in figure 4 appear to give a clear indication regarding the effect of local forcing leading to the observed MLD variability.

\subsection{Coupling among wind, wave and observed $M L D$}

Various scattered plots (figure 6) have been plotted among wind speed, wave parameters and MLD considering all observation of three different phases as explained earlier to understand the coupling or interdependence between different parameters. As there was a steady increase in the wind and wave activity during phase II, separate scatters are also plotted in this case (figure 7).

The scatter between wind speed and Hs as shown in figure 6(a) reveals that the two parameters are weakly correlated (correlation coefficient $r=0.34$ ). The thick line plotted over the scatter is the JONSWAP (Hasselmann et al 1973) model for fully developed sea $\left[\mathrm{Hs}=(0.243 / \mathrm{g}) / \mathrm{U}^{2}\right]$. The data scattered to the right of the line, are the growing windseas and the data closer and above it are either fully developed waves or swells propagating into the observation site. There can be a significant amount of wave breaking during these observations. However, the breaking is almost nil or restricted to the high frequency part of the wave spectrum for about $30 \%$ of the observations. It may be noted that the observed MLD shows negative correlation 


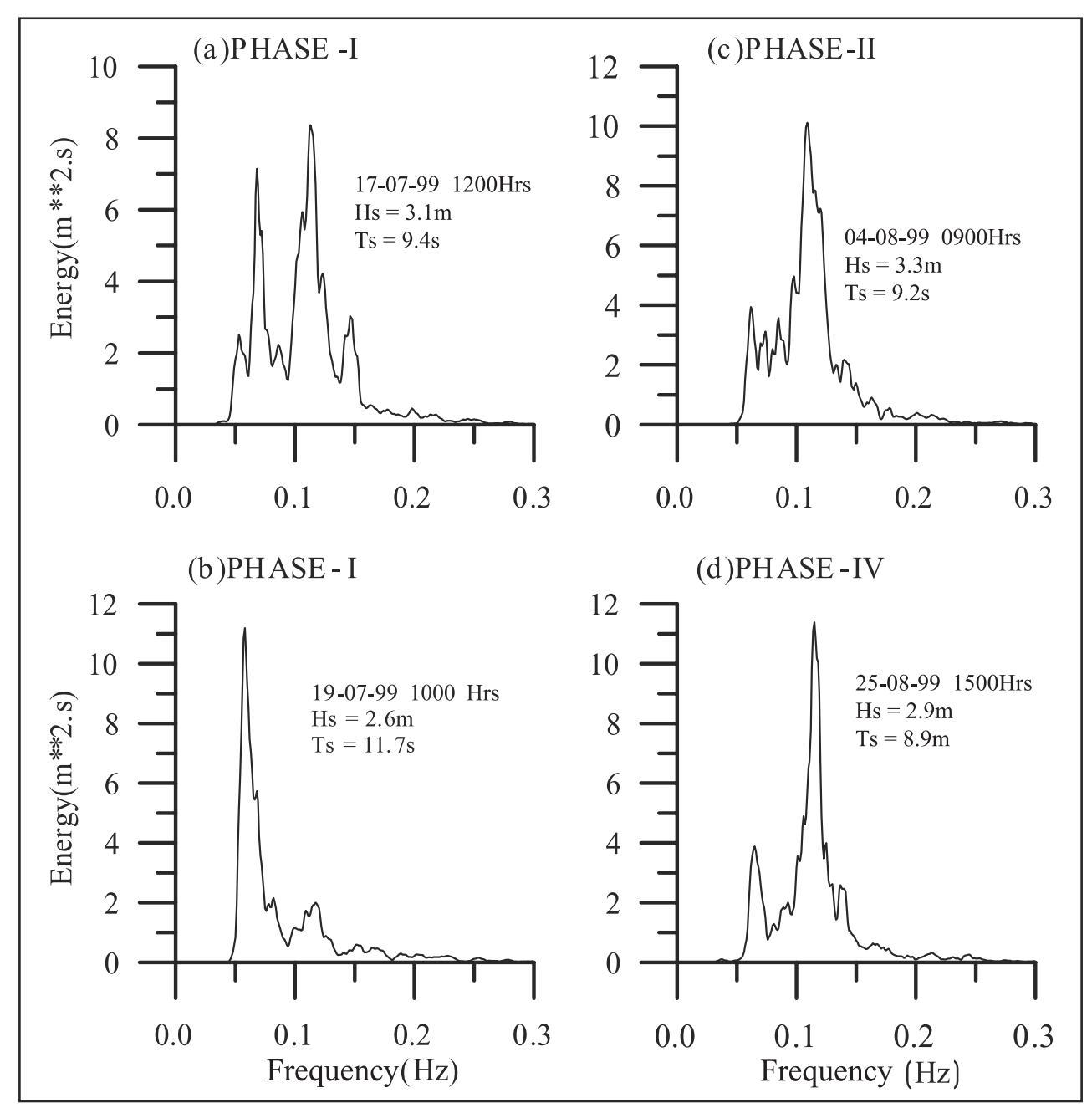

Figure 5. Four typical wave spectra observed during BOBMEX-99.

with wind speed, Hs and Ts. Comparatively, MLD shows a better correlation with Ts compared with wind speed (U) and Hs. The power law relationships between all the observed parameters as shown in figure 6 further increased the scatters for all the parameters along with the decrease in coefficients of correlation between the parameters considered. Therefore, the observed MLD variations in case of phase II alone are plotted against $\mathrm{U}, \mathrm{Hs}$ and Ts including Hs against U (figure 7). In this case, higher correlations $(r=0.47$ to 0.54$)$ have been observed between the parameters shown. Hence, figure 7 gives an indication that, there is a possibility to predict the MLD variability during such events when wind and wave activity is consistently strong over longer duration.

\subsection{Statistical/empirical predictive models for $M L D$}

From the previous discussion on the observed U, $\mathrm{Hs}$, Ts and MLD variations during BOBMEX, it appears feasible to formulate a simple statistical model for the prediction of MLD variability due to forced mixing. Before formulation of a new relation for MLD, two simple empirical models have been tested in this investigation. To start with, Laevastu's (1960) simple empirical model (depth of mixing $\mathrm{Dm}=12.5 \times \mathrm{Hs}$ ) has been tested with the observations of all the three phases combined (figure 8(a), Dm replaced with MLD). The distribution of observed and computed MLD using this model shows a higher departure from the line of no deviation. Therefore, the model constant has been estimated from the observed data (inverse fit) and plotted along with the line of no deviation (figure 8b). The revised relationship $(\mathrm{MLD}=21.5 \times \mathrm{Hs})$ through inverse least square fit could estimate the MLD more accurately with minimum error. However, the modified relation is only a statistical fit to the data which may not have much relevance with other data sets. The second model proposed by Mazeika (1960) considered the mixed layer depth as a function of wave ampli- 


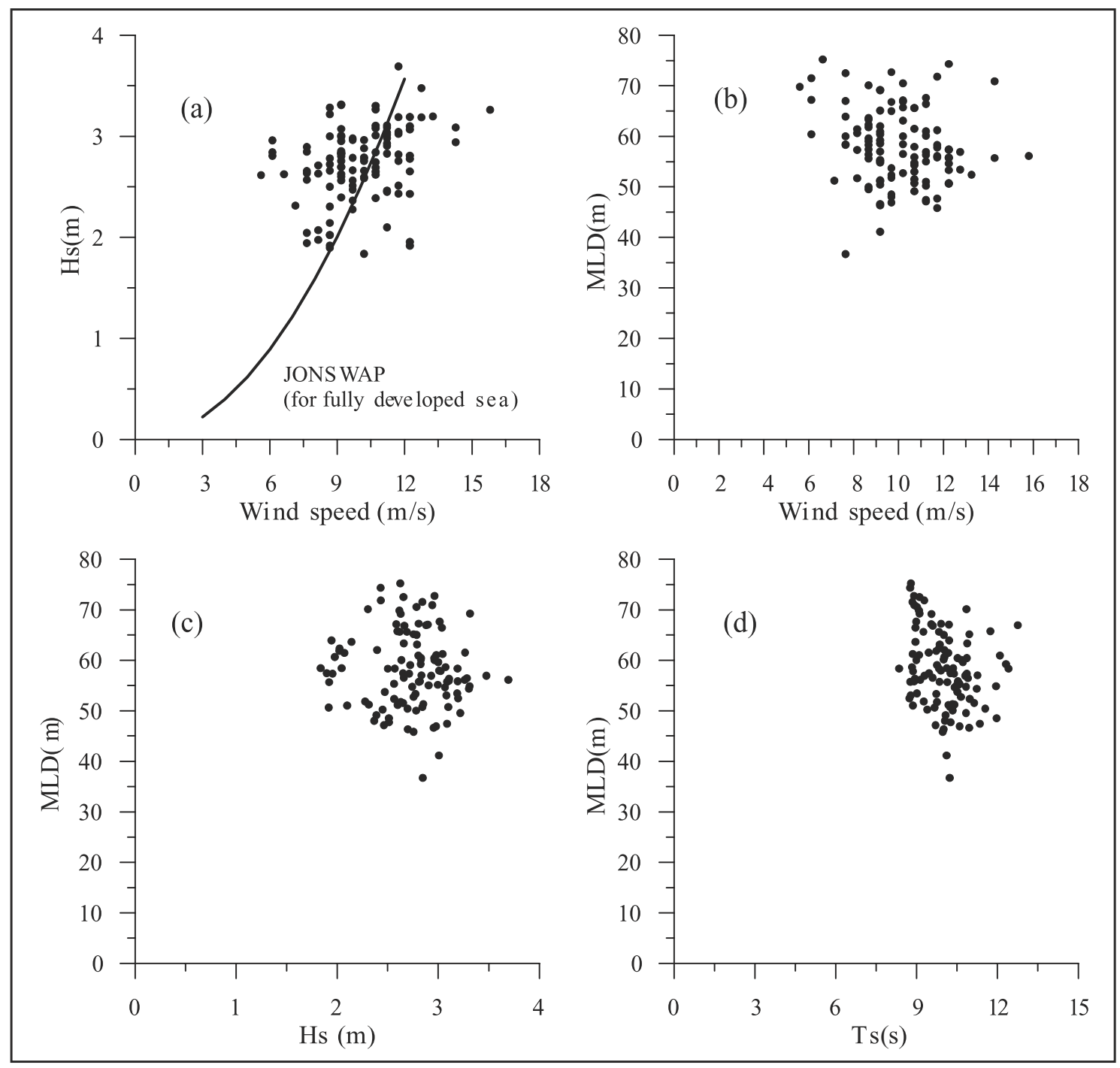

Figure 6. Scatter plots showing coupling among wind, wave and observed MLD variations (3 phases combined).

tude, wave length and a mixing parameter $(\mathrm{Km})$. Further to relate the mixing parameter values with the thermocline stability and the wave parameters, Mazeika introduced another parameter known as the sea-state parameter $\eta(=\mathrm{Hs} \times \mathrm{Ts})$. Hence, the scatter between MLD and $\eta$ shown in this case (figure 8c) appears to be slightly better than MLD and Ts as in figure 6(d). Having analysed these parameters and their relationships to the observed MLD variability during the BOBMEX mission, it is not feasible to predict MLD using the wave parameters alone. Probably a better choice would be to introduce U, Hs and Ts for the development of an improved simple empirical relation for a gross estimation of mixed layer depth.

\subsection{Formulation of the proposed model}

It is well understood that wind is the generating force for surface waves and current which are the primary causes for mechanical mixing of water at the sea surface. However, the prevailing surface waves and current very rarely relate to the prevailing winds. This is because, the winds are never consistent, and they vary in space and time. Therefore, the proposed parameters as indicated in the previous section would improve the model formulation as explained below.

First of all, the MLD values have been estimated following Laevastu (1960) and the same are substracted from the observed MLD to compute the residuals. In the second step, the residual values of MLD (error estimates) are correlated with the prevailing wind and Ts. The prevailing wind is directly responsible for the growth as well as breaking of waves which results in turbulence and mixing. Secondly, the parameter Ts takes care of the swell waves which propagate from a longer distance and significantly contribute towards forced mixing. Therefore, through 


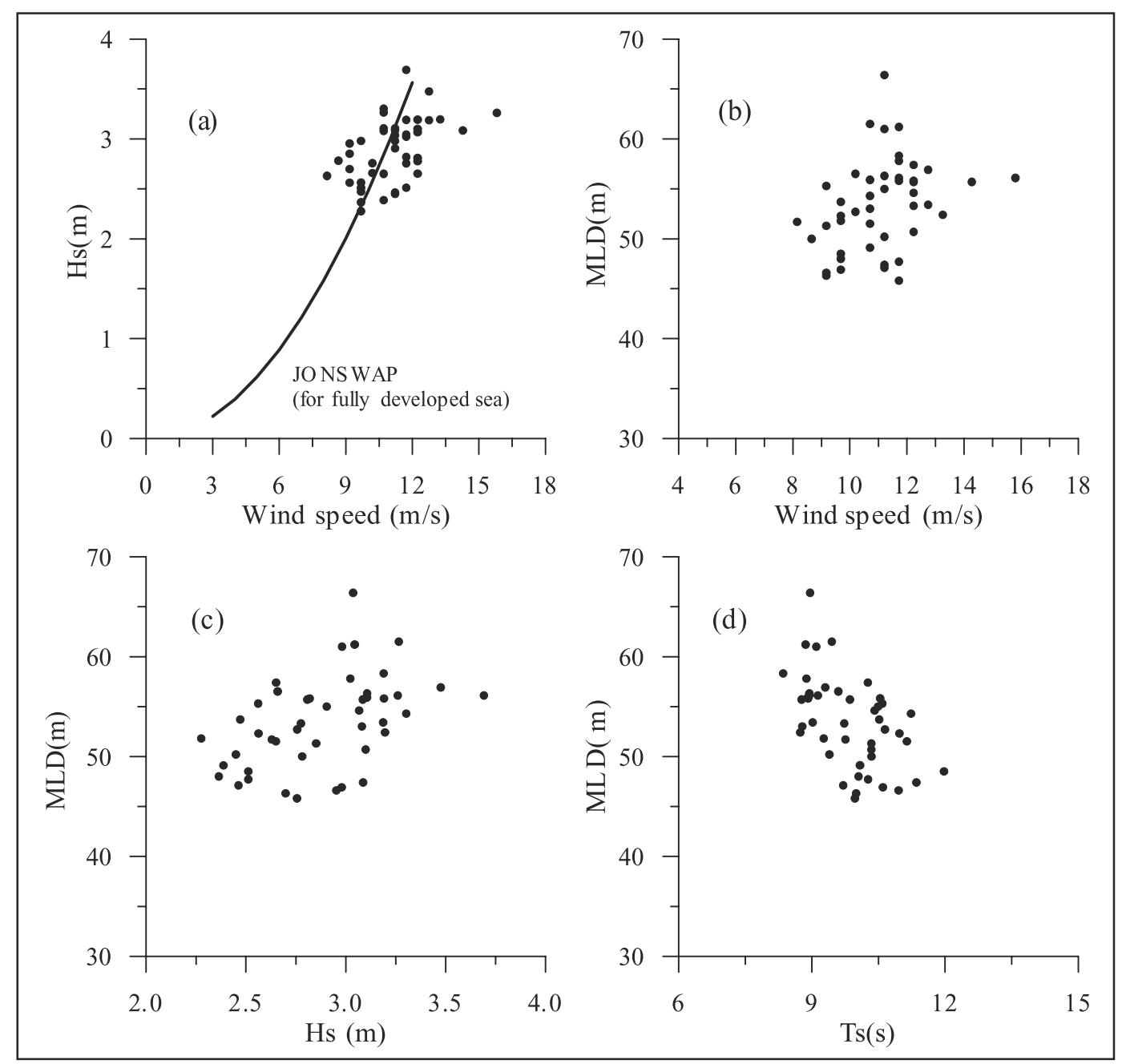

Figure 7. Scatter plots showing coupling among wind, wave and observed MLD variations for phase II alone.

least square approximation and subsequent sensitive analysis it is found that the product of $\mathrm{U}$ and Ts have maximum correlation with the error estimates. Hence, the final relation as an extension of Laevastu's model is obtained as follows:

$$
\mathrm{MLD}=12.5 \times \mathrm{Hs}+0.2(\mathrm{U} \times \mathrm{Ts}) .
$$

The observed and predicted MLD using the above relation is shown in figure $8(\mathrm{~d})$ which has a mean deviation of $3.8 \mathrm{~m}$ and standard error of $10.4 \mathrm{~m}$. In this equation, the first term on the right side is the Laevastu's model and the second term which accounts for about $50 \%$ of the observed MLD variation is the additional term introduced statistically based on the present analysis. As the above three variables such as $\mathrm{Hs}, \mathrm{U}$ and Ts are often independent of each other, the new relation is expected to yield better results which will be discussed in the following section.

\subsection{Observed and predicted $M L D$ using proposed model}

The proposed model estimates of MLD for the three different phases are plotted in figure 9. The observed MLD is shown with solid line and the predicted values are shown with solid circles. The triangles indicate the MLD based on the density criterion which are in good agreement with the MLD based on temperature criterion as shown in the form of a scatter diagram in figure 3 earlier. It may be seen that the observed and predicted MLD compare well in the case of phase II. The mean deviations (MD) and standard error (SE) estimates are also given in the respective plots (figure 9). The MD and SE vary from -4.3 to 12.2 and 5.7 to $10.8 \mathrm{~m}$ respectively. The highest departure between predicted and observed MLD is seen in the case of phase IV. Interestingly, the fluctuations which are seen in the observed MLD are also noticed in the predicted values. However, 


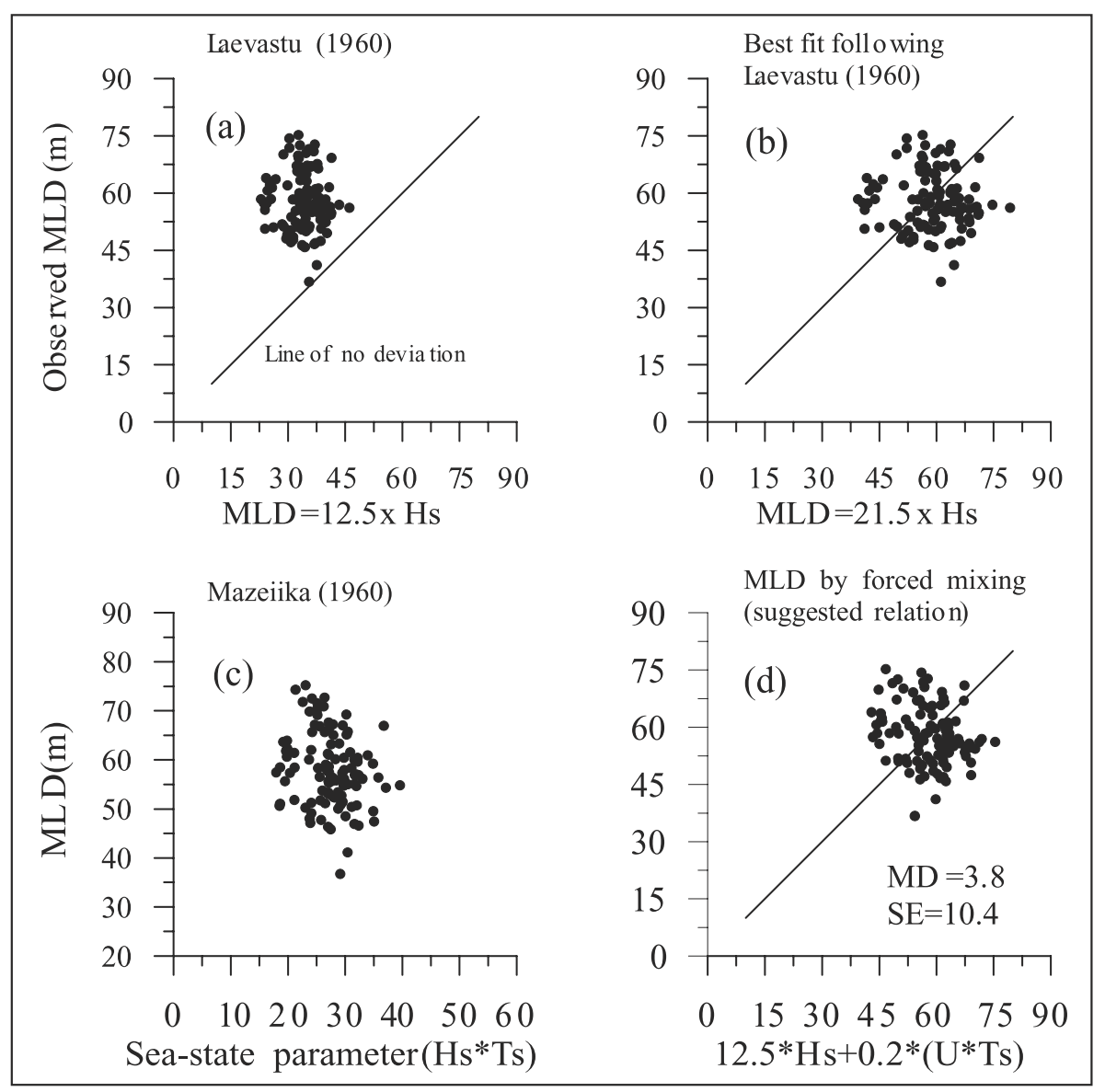

Figure 8. Statistical prediction models for MLD using data from all three phases of BOBMEX-99 in the central Bay of Bengal.

the peaks do not match with each other. Therefore, the observed and predicted MLD series pertaining to three different phases were subjected to cross-correlation analysis. It is noticed that the observed and predicted MLD show maximum correlation with a lag of 9 hours with the future wind and wave parameters where the sampling interval is 3 hours. Therefore, the observed and predicted MLD values are plotted in figure 10 in the same way as in figure 9 considering a lag of 9 hours. The comparison is very encouraging. It may be seen that, the observed and predicted peaks match very well in figure 10 although their magnitudes vary sometimes significantly. The MD and SE have decreased to some extent in case of figure 10 compared to figure 9. By and large, the proposed empirical model could simulate the MLD variability and its trend by considering the future 9 hours wind and wave parameters. It suggests that, the observed MLD variability at the time-series station is due to both local and remote forcing. The wind and wave conditions that prevailed over about 500 kilometers away and crossed the time-series location after about 9 hours perhaps could con- tribute for the MLD variability and its oscillations at the observation site. The length and time scales given here are only an approximation which may vary to some extent depending on the behavior of monsoon winds across the region of study. Therefore, the MLD variations at the desired location can be easily estimated using the instant satellite measurements at a far off or remote area which has a probable contribution towards such variations.

One of our earlier investigations (Hareesh Kumar et al 2001) suggested intraseasonal oscillations in the observed meteorological and oceanographic fields such as the wind and MLD etc. utilising the same data set used here. Further, the study concluded that, the MLD variability was dominated by remote forcing compared to local forcing. Perhaps, it is not impossible to quantify the magnitudes of local (forced mixing) and remote forcing using such measurements. However, the present analysis confirms that, the variations of MLD at the time-series station is due to the wind field variation over a longer oceanic region that influenced the observed MLD variation at the up wind extreme. 


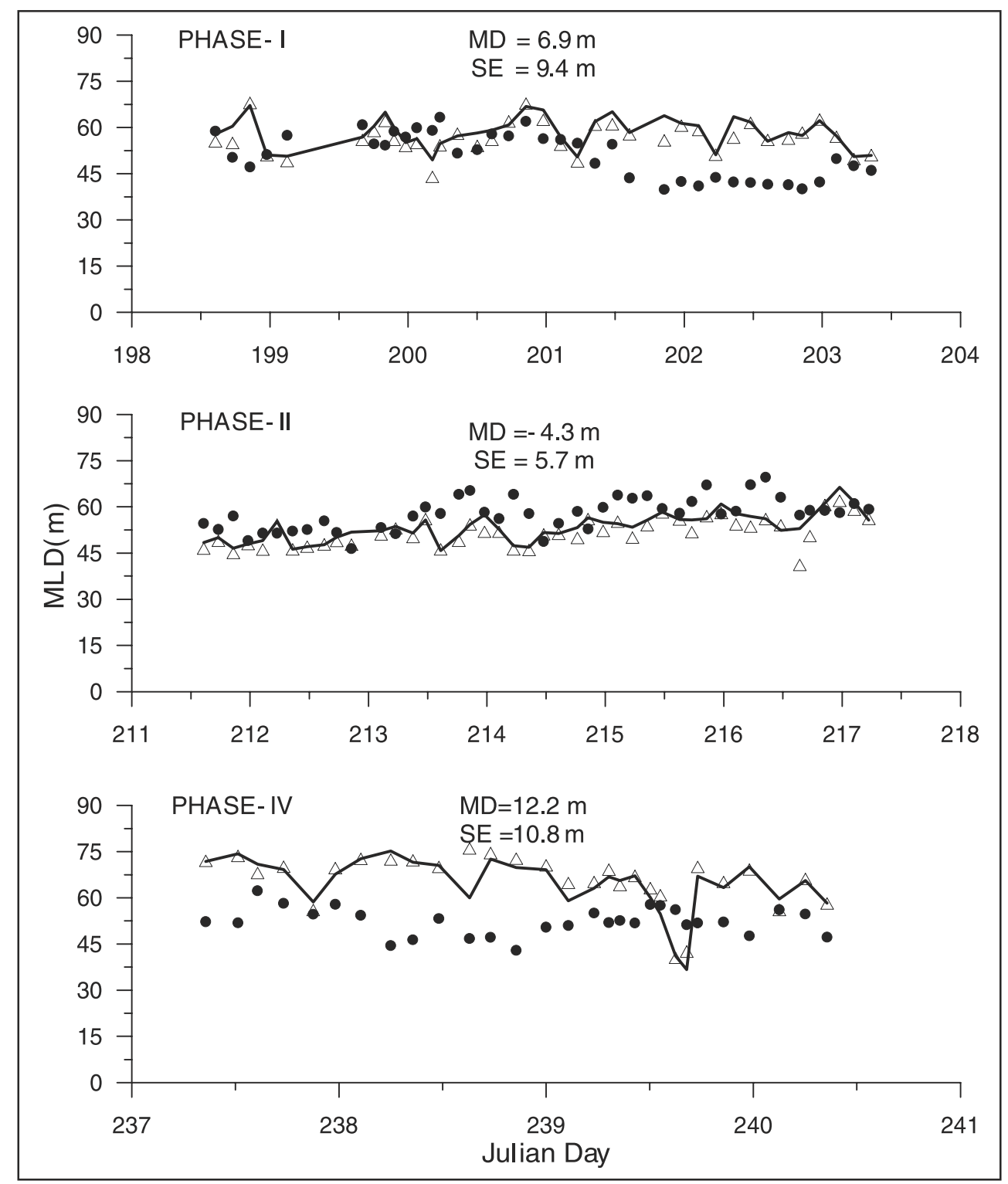

Figure 9. Comparison between observed (solid line) and predicted (circles) MLD during BOBMEX-99. MLD based on density is shown with the triangles.

\section{Conclusions}

Time-series wind, wave and mini STD data collected onboard INS Sagardhwani in the central Bay of Bengal during the BOBMEX mission (JulyAugust 1999) have been utilised in this investigation to study the observed MLD variations due to forced mixing. One of the earlier studies using the same data set indicated that the MLD variations at the observation site was predominately due to remote forcing compared to local forcing. In this study, the observed wind speed, the significant wave height and period have been considered for a statistical parameterisation of mixed layer depth (MLD) due to the combined effect of forced mixing (local activity) and the remote forcing although it does not have a sound physical basis. In this regard, two simple models for the determination of MLD by forced mixing are utilized to test the influence of local wind and wave activity on the observed MLD. Based on the interrelationships between different wind and wave parameters and MLD, a simple empirical model has been proposed in this study for the determination of MLD. It is seen that the proposed model is able to predict the observed MLD oscillations to a large extent if a future time-lag of 9 hours is considered. It indirectly suggests that, the MLD variations at the desired location can be easily estimated using the instant satellite measurements of the propagating disturbance from a far off location which need further studies. The comparisons 


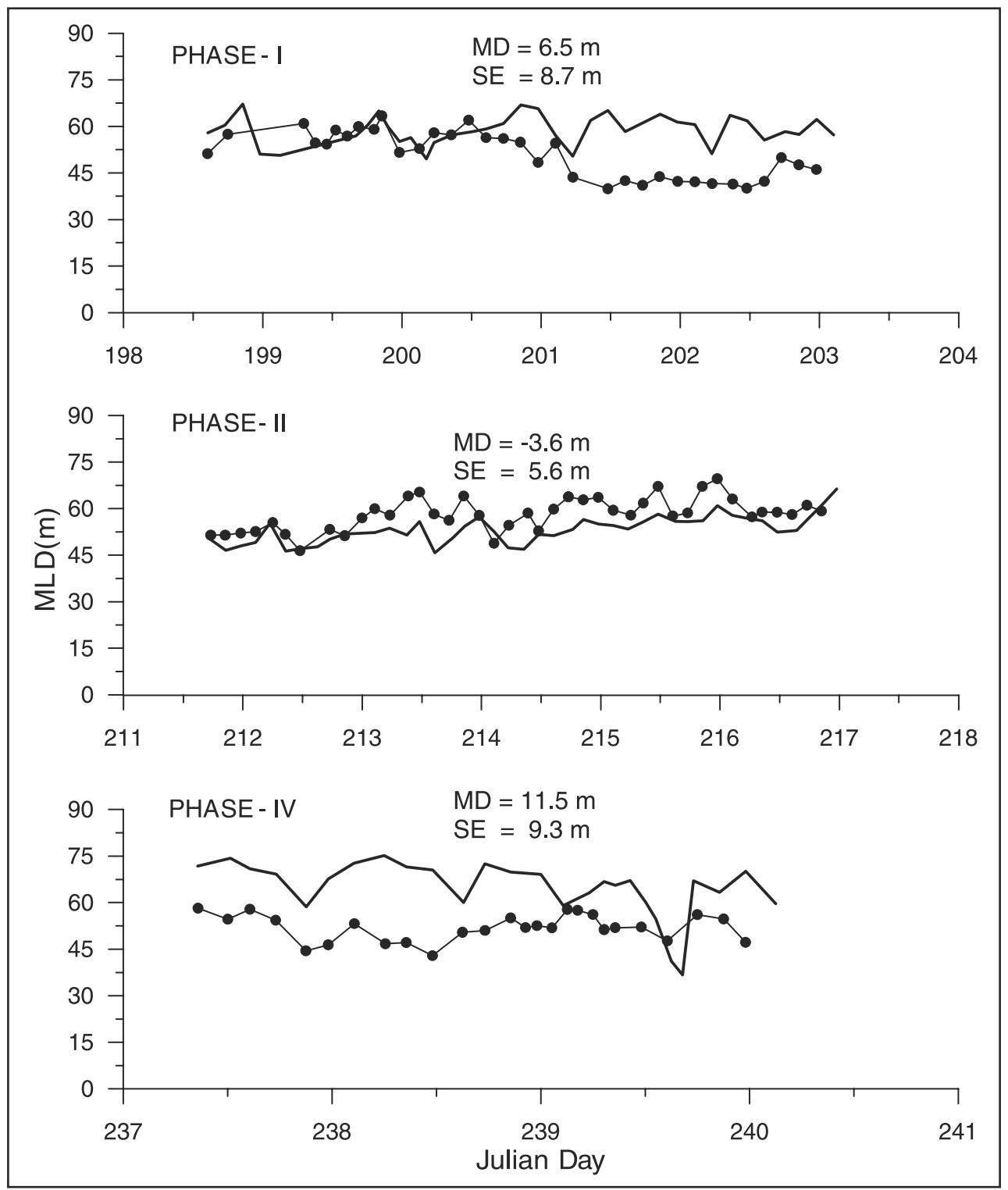

Figure 10. Comparison between observed (solid line) and predicted (circles) MLD during BOBMEX-99 assuming 9-hours lag.

between the observed and predicted MLD using the new model revealed that the observed MLD variability at the central Bay is due to both local and remote forcing. It is unlikely that, the proposed model will be able to predict the absolute MLD variations accurately since there are a number of other factors (not discussed here) which also contribute significantly. However, it is believed that this model will be able to provide an approximate estimation of MLD if one uses the currently available satellite data covering a larger oceanic region. The parameters considered are to be incorporated into this proposed relation by suitable averaging of satellite measurements such as the wind, which is more or less steady during the southwest monsoon season.

\section{Acknowledgements}

The authors express their sincere thanks to the Director, NPOL for providing the necessary facilities and support. They are also grateful to all the participants onboard INS Sagardhwani during the different phases of the BOBMEX-99 mission. Special thanks are due to Dr. P V Hareesh Kumar for providing the processed mini STD data for the estimation of MLD.

\section{References}

Bhat G S, Gadgil S, Hareesh Kumar P V, Kalsi S R, Madhusoodanan P, Murty V S N, Prasada Rao C V K, Ramesh Babu V, Rao L V G, Rao R R, Ravichandran M, 
Reddy K G, Sanjeeva Rao P, Sengupta D, Sikka D R, Swain J and Vinayachandran P N 2001 BOBMEX: The Bay of Bengal Monsoon Experiment; Bull. Am. Meteorol. Soc. 82(10) 2217-2243

Hasselmann K, Barnett E, Bouws H, Carlson D E, Cartwright K Enke, Ewing J A, Gienapp H, Hasselmann D E, Krusemann P, Meerburg A, Muller P, Olbers D J, Richter K, Sell W and Walden H 1973 Measurement of wind-wave growth and swell decay during the Joint North Sea Project (JONSWAP); Dtsch. Hydrogr. Z, A 8(12)

Hastenrath S and Lamb P J 1979 Climatic atlas of the Indian Ocean, Part-I, Surface Climate and atmospheric circulation; (USA: The University of Wisconsin Press) pp. 97

Hastenrath S and Greischar L L 1989 Climatic atlas of the Indian Ocean, Part-III: Upper-Ocean Structure; (USA: The University of Wisconsin Press) pp. 247

Hareesh Kumar P V, Prasada Rao C V K, Swain J and Madhusoodanan P 2001 Intra-seasonal oscillations in the central Bay of Bengal during summer monsoon 1999; Curr. Sci. 80(6) 786-790

Kitaigorodskii S A 1960 Calculation of the thickness of the layer in which wind-induced mixing occurs in an ocean; Izv. Akad. Nauk. USSR Ser. Geophys. 3 423-431

Laevastu T 1960 Factors affecting the temperature of the surface layer of the sea; Soc. Scient. Fennica, Comm. Phys-Mathem 25(1) pp. 136

Lumby J R 1955 The depth of the wind-produced homogeneous layer in the ocean; Fish. Invest. Lond. Ser. 2 2(2) pp. 12

Mazeika P A 1960 Prediction of thermohaline depth; US Naval Oceanogr. Office Technical Report No. TR-104 pp. 79

Rosby C and Montgomery N 1935 The layer of frictional influence in wind and ocean currents; Papers in Phys. Oceanogr. Meteorol. 3(3)

Swain J 1999 Wave climate simulation for Indian seas; Research Report No. NPOL RR-4/99 pp. 34

Swain J, Prasada Rao C V K, Hareesh Kumar P V, Shukla R K, Unny V K, Mohan Kumar N and Raghunath Rao A 2000 Observed wind and wave characteristics in the south central Bay of Bengal during BOBMEX99; Proceedings TROPMET 2000: Ocean and Atmosphere 406-409

Young I R and Holland G J 1996 Atlas of the oceans: Wind and wave climate; (USA: Pergamon, Elsevier Science) pp. 241 